\title{
ORGANOGÊNESE EM CAPÍTULOS FLORAIS E AVALIAÇÃO DE CARACTERÍSTICAS ANATÔMICAS DA FOLHA DE Gerbera jamesonii Adlam
}

\author{
Capitulum organogenesis and anatomical characterization of Gerbera jamesonii Adlan leaves
}

\author{
Rodrigo Kelson Silva Rezende ${ }^{1}$, Luciano Vilela Paiva², Renato Paiva ${ }^{3}$, Antônio Chalfun Júnior ${ }^{4}$, \\ Paula Pereira Torga ${ }^{5}$, Evaristo Mauro de Castro ${ }^{6}$
}

\begin{abstract}
RESUMO
Objetivou-se determinar um protocolo de micropropagação por organogênese indireta em capítulos florais de gérbera (Gerbera jamesonii Adlam) e comparar as características anatômicas de folhas de gérbera obtidas in vitro com as mantidas em condições in vivo. Capítulos florais de gérbera foram utilizados como fonte inicial de explantes para a indução de calos e regeneração. As brotações obtidas foram enraizadas in vitro e, após 30 dias, as plântulas foram aclimatizadas. Posteriormente, foram realizados estudos anatômicos de folhas provenientes do cultivo in vivo e in vitro. Obtiveram-se em média 3,2 brotações e 6,6 folhas a partir da indução de calos em capítulos florais de gérbera. Foi observada a formação de raízes na ausência e na presença de ANA, obtendo-se $100 \%$ de enraizamento. A suplementação do meio de cultura com doses crescentes de ANA promoveram um aumento linear no número de raízes e no comprimento médio de raízes. As plântulas provenientes do cultivo in vitro apresentaram taxa de $100 \%$ de sobrevivência na aclimatização. As estruturas foliares desenvolvidas in vivo apresentaram as epidermes adaxial e abaxial, parênquimas paliçádico e esponjoso mais espessos que no cultivo in vitro. O sistema vascular em folhas produzidas in vivo é mais desenvolvido que in vitro.
\end{abstract}

Termos para indexação: Micropropagação, Aclimatização, Gerbera jamesonii.

\section{ABSTRACT}

The objective was to determine a micropropagation protocol for indirect organogenesis and to compare the anatomical characteristics of leaves of gerbera (Gerbera jamesonii Adlam) obtained in vitro with the leaves maintained in vivo conditions. Capitulum explants of gerbera were taken as an initial source of explants to induce callus and regeneration. The obtained shoots were rootted in vitro and after 30 days seedlings were acclimatized.Thus, anatomical studies of leaves originating from of the in vivo and in vitro cultivation were taken. On average it was obtained 3,2 shoots and 6,6 leaves from the induction of callus in capitulum explants of gerbera. The formation of roots was observed in the presence and absence of NAA, obtaining $100 \%$ of rooting. The supplementation of NAA to the medium promoted a linear increase in the number of roots and in the mean length of roots. Seedlings from the in vitro cultivation showed rate of $100 \%$ of survival in the acclimatization. The foliar structures developed in vivo showed adaxial epidermis, palisade parenchyma, spongy parenchyma and abaxial epidermis thicker than in the in vitro cultivation. The vascular system in leaves produced in vivo is more developed than in vitro.

Index terms: Micropropagation, Acclimatization, Gerbera jamesonii.

\section{(Recebido em 8 de setembro de 2005 e aprovado em 30 de outubro de 2006)}

\section{INTRODUÇÃO}

A gérbera (Gerbera jamesonii Adlam) é uma espécie ornamental da família Asteraceae, cujas flores são utilizadas para corte e vaso sendo vendidas no comércio com grande importância econômica. Sua propagação natural pode ser feita por meio de sementes ou por divisão de touceiras. Ambos os métodos são inconvenientes quando pensa-se em propagação em âmbito comercial, pois, suas sementes originam progênies desuniformes pela alogamia da espécie e a divisão de touceiras dissemina e acumula doenças por meio de sucessivas gerações (PIERIK et al., 1975).

O emprego da cultura de tecidos tem sido crescente para essa herbácea, tornando-se uma alternativa bastante viável para sua propagação assexual. O método mais indicado para o estabelecimento inicial da cultura é o que

\footnotetext{
${ }^{1}$ Engenheiro Agrônomo, Doutorando em Fisiologia Vegetal - Departamento de Biologia/DBI - Universidade Federal de Lavras/UFLA - Cx. P. 3037 37200-000 - Lavras, MG - rkelsonsr@yahoo.com.br

2Engenheiro Agrônomo, Doutor, Professor Adjunto - Departamento de Química/DQI - Laboratório Central de Biologia Molecular/LCBM - Universidade Federal de Lavras/UFLA - Cx. P. 3037 - 37200-000 - Lavras, MG - luciano@ufla.br

${ }^{3}$ Engenheiro Agrônomo, PhD., Professor Associado - Departamento de Biologia/DBI - Universidade Federal de Lavras/UFLA - Cx. P. 3037 - $37200-000$ Lavras, MG - renpaiva@ufla.br

${ }^{4}$ Engenheiro Agrônomo, PhD., Professor Adjunto - Departamento de Biologia/DBI - Universidade Federal de Lavras/UFLA - Cx. P. 3037 - $37200-000$ Lavras, MG - chalfunjunior@ufla.br

${ }^{5}$ Engenheira Agrônoma, Mestranda em Genética e Melhoramento de Plantas - Departamento de Biologia/DBI - Universidade Federal de Lavras/UFLA Cx. P. 3037 - 37200-000 - Lavras, MG - paulaptorga@yahoo.com.br

${ }^{6}$ Engenheiro Florestal, Doutor, Professor Adjunto - Departamento de Biologia/DBI - Universidade Federal de Lavras/UFLA - Cx. P. 3037 - $37200-000$ -

Lavras, MG - emcastro@ufla.br
} 
emprega meristemas. Entretanto, ele demanda um grande número de plantas adultas, que são destruídas para o fornecimento de explantes iniciais. Dessa forma, a utilização de explantes como capítulos florais, surge como uma alternativa de propagação in vitro de gérbera. Nesse caso, as plantas matrizes podem vir a emitir novas flores que servirão como fonte de explantes (REZENDE, 2005).

A organogênese in vitro envolve uma variedade de seqüências complexas de desenvolvimento, resultantes da manipulação experimental de partes de uma planta, culminando na formação de primórdios de órgãos ou plantas inteiras (HICKS, 1980). Quando a organogênese ocorre a partir de tecidos do explante ou de pequenas proliferações dos mesmos, ainda sobre o explante inicial sem a formação do calo, denomina-se organogênese direta. A via indireta é caracterizada quando a organogênese ocorre a partir de calos isolados do explante inicial (STIRMART, 1986). A organogênese envolve a diferenciação de brotações e raízes durante o desenvolvimento vegetal. As brotações são induzidas em um meio de cultura enriquecido com citocininas e enraizadas em um meio contendo auxina (GRATTAPAGLIA \& MACHADO, 1998). As auxinas mais utilizadas para a indução de raízes in vitro são o ácido indol-3-acético (AIA), ácido naftaleno-acético (ANA) e o ácido indol-butírico (AIB), sendo esses normalmente utilizados em baixas concentrações no meio de cultura (GEORGE \& SHERRINGTON, 1984; ZIMMERMAN, 1981). Certas espécies enraizam com dificuldade, ou não enraizam, mesmo na presença de auxinas. Para algumas espécies dispensa-se o uso de auxinas no seu enraizamento (ROHR \& HANUS, 1987).

Após a etapa de enraizamento in vitro as plântulas são aclimatizadas normalmente em ambiente com alta luminosidade e baixa umidade. A aclimatização envolve o transplantio da plântula da condição in vitro para a casade-vegetação o que, geralmente, é uma fase crítica e que pode ser fator limitante para o processo de micropropagação de algumas espécies (TORRES et al., 1998). Vários fatores estão envolvidos na morte ou sobrevivência das plântulas durante a aclimatização, tais como o genótipo, estresse hídrico, alteração do metabolismo heterotrófico para autotrófico, infecção por patógenos e o estresse pela alteração na radiação. $\mathrm{O}$ ambiente de cultivo pode afetar e conduzir a diferentes atividades enzimáticas, resultando em várias mudanças nos processos metabólicos da planta (DEBERGH \& MAENE, 1981).

A desordem estrutural e funcional nas plântulas in vitro é resultado de complexos e múltiplos fatores do meio de cultura. A conseqüência, é uma baixa taxa de sobrevivência das plantas quando transferidas para condições ex vitro (ZIV, 1987). Pasqual et al. (1997) afirmam que, durante o processo de transferência para a condição ex vitro, a cutícula é freqüentemente menos desenvolvida em razão da umidade relativa no interior dos frascos ser relativamente alta. Como conseqüência, ocorre elevada perda de água durante o processo de aclimatização. As modificações manifestadas, principalmente nas folhas, afetam os principais processos executados por elas, ou seja, a fotossíntese e as trocas gasosas. $\mathrm{O}$ ambiente de cultivo pode afetar e conduzir a diferentes atividades enzimáticas, resultando em várias mudanças nos processos metabólicos da planta (DEBERGH \& MAENE, 1984).

Dessa forma, a avaliação das mudanças estruturais que ocorrem em um tecido ou órgão formado em condições in vitro é de grande valia para se descobrir a real eficiência do processo organogenético e a funcionabilidade do novo órgão, tornando-se pré-requisito indispensável para o desenvolvimento de protocolos de micropropagação de plantas (SOARES, 2003).

Objetivou-se, no trabalho, determinar um protocolo de micropropagação por organogênese indireta em capítulos florais de gérbera e comparar as características anatômicas de folhas de plantas obtidas in vitro e em condições in vivo.

\section{MATERIAL E MÉTODOS}

\section{Organogênese indireta a partir de capítulos florais de gérbera}

Plantas matrizes de Gerbera jamesonii cv. Jaguar Cream, com aproximadamente 90 dias, foram cedidas pela empresa Multiflores (Lavras - MG).

Foram coletados capítulos florais, com duas ou três fileiras de flores abertas, tendo sido retiradas as lígulas e todas as flores do centro do capítulo. Em seguida, os capítulos foram imersos em hipoclorito de sódio $(2,0 \%$ de cloro ativo), por um período de 60 minutos.

Cada capítulo foi então lavado em água destilada por três vezes, cortado radialmente em quatro partes que foram inoculadas em meio de cultura MS 50\% (MURASHIGE \& SKOOG, 1962), suplementado com 3\% de sacarose, $0,7 \%$ de ágar, adicionando $6,0 \mathrm{mg} \mathrm{L}^{-1}$ de BAP e $0,5 \mathrm{mg} \mathrm{L}^{-1}$ de AIA (ARELLO, 1998). O pH do meio de cultura foi ajustado para $6,0 \pm 0,1$ antes da autoclavagem a $121^{\circ} \mathrm{C}$, durante 20 minutos.

O experimento foi constituído de 50 tubos de ensaio com 1 explante por tubo, sendo mantido em sala de crescimento a $25 \pm 2^{\circ} \mathrm{C}$ de temperatura por um período de 
30 dias na ausência de luz. Posteriormente, foi colocado para se desenvolver por 50 dias sob fotoperíodo de 16 horas e irradiância de fótons de $43 \mu \mathrm{mol} \mathrm{m} \mathrm{m}^{-2} \mathrm{~s}^{-1}$.

A avaliação da porcentagem de capítulos florais com formação de calos foi feita aos 30 e 60 dias após a inoculação por meio de contagem e análise qualitativa.

Foi avaliado também, por contagem, o número médio de brotações e folhas por explante, 80 dias após a inoculação.

\section{Efeito de diferentes doses de ANA no enraizamento in vitro de brotações}

Brotações obtidas a partir de capítulos florais in vitro, apresentando em média 3 a 4 folhas, foram inoculadas em tubos de ensaio contendo meio de cultura MS 50\%, suplementado com $3 \%$ de sacarose, $0,7 \%$ de ágar, $0,1 \%$ de carvão ativado, contendo diferentes concentrações de ácido naftaleno-acético (ANA), 0,0; 2,0 e 4,0 mg L $\mathrm{m}^{-1}$, tendo o pH ajustado para 5,6 $\pm 0,1$. Após a inoculação, os explantes foram mantidos em sala de crescimento a $25 \pm$ $2^{\circ} \mathrm{C}$, fotoperíodo de 16 horas e irradiância de fótons de $43 \mu \mathrm{mol} \mathrm{m} \mathrm{m}^{-2}$.

Utilizou-se o delineamento experimental inteiramente casualizado, com 10 repetições por tratamento (uma brotação/tubo). Trinta dias após a inoculação, foi avaliada a porcentagem de enraizamento das brotações, por meio de contagem. Das plantas enraizadas, foram obtidos dados sobre número e comprimento médio de raízes, que foram submetidos à análise de variância. Em caso de observação de diferenças significativas, efetuaramse análises de regressão.

\section{Aclimatização de plântulas}

Após serem mantidas por 30 dias no meio de cultura de enraizamento, as plântulas foram transferidas para tubetes $(120 \mathrm{~mL})$, preenchidos com substrato comercial 30/10 da empresa Vida Verde, sendo posteriormente cobertas com sacos plásticos transparentes para manter a umidade e mantidas em sala de aclimatização, sob fotoperíodo de 12 horas e irradiância de $60 \mu \mathrm{mol} \mathrm{m} \mathrm{m}^{-2} \mathrm{~s}^{-1}$.

Após 14 dias, avaliou-se a taxa de sobrevivência das plântulas, levando-se em consideração o aspecto visual das mesmas.

\section{Anatomia de folhas produzidas por cultivo in vivo e in vitro}

Para as análises in vivo, folhas completamente expandidas foram coletadas ao acaso de plantas matrizes de gérbera cv. Jaguar Cream, com aproximadamente 90 dias, mantidas em casa-de-vegetação, na empresa Multiflores
(Lavras-MG) a $35 \pm 2^{\circ} \mathrm{C}$ e $40 \%$ de umidade relativa do ar. Coletou-se também ao acaso, folhas oriundas de plântulas obtidas pelo cultivo in vitro, na ocasião de transferência das mesmas para a sala de aclimatização. As folhas oriundas de ambos os cultivos foram conservadas em álcool $70 \%$ (v/v).

De cada tratamento, foram escolhidas ao acaso cinco plantas e, de cada uma, foi retirada uma folha da qual foram extraídos segmentos de $0,5 \mathrm{~cm}^{2}$ da região mediana. Os estudos anatômicos foram realizados com base no exame microscópico de seções obtidas à mão livre, segundo a metodologia descrita por Johansen (1940) e Sass (1951). A coloração dos cortes anatômicos foi efetuada pelo processo de dupla coloração com safranina-azul de astra (BUKATSH, 1972). Foram efetuadas medições de espessura das epidermes adaxial e abaxial e dos parênquimas esponjoso e paliçádico, com auxílio de lente ocular micrométrica, em microscópio de campo claro Carl Zeiss-amjlival. Posteriormente, essas lâminas foram fotomicrografadas utilizando-se um microscópio Olympus BX 60 e filme ASA 100 colorido.

As medições de espessura foram analisadas utilizando-se delineamento inteiramente casualizado com cinco repetições por tratamento, sendo cada repetição composta por três medidas. As médias foram comparadas pelo teste de F.

\section{RESULTADOS E DISCUSSÃO}

\section{Organogênese indireta a partir de capítulos florais de gérbera}

Após um período de 30 dias da inoculação inicial no meio de cultura sugerido por Arello (1998), 76\% dos capítulos florais formaram calos não havendo formação de calos após esse período. Os calos se apresentaram grandes, claros, não friáveis e não vitrificados.

Esse mesmo meio de cultura, após um período de 80 dias da inoculação inicial, foi eficiente em promover a formação de 3,2 brotações e 6,6 folhas por explante em média, a partir da indução de calos em capítulos florais de gérbera.

Esse resultado infere na alta capacidade da gérbera em formar brotos e folhas a partir da indução de calos em capítulos florais, o que viabiliza a micropropagação da cultura.

Pierik et al. (1975) também obtiveram indução de calos em capítulos florais de gérbera cv. Fleur e Florence, deixando-os armazenados 30 dias no escuro e 30 dias na presença de luz. Após um período de 60 dias, os autores encontraram a formação de 3 brotos por explante e esse número foi aumentado para $4 \mathrm{com}$ aumento do tempo de cultivo variando de 80 a 100 dias. 
Efeito de diferentes doses de ANA no enraizamento in vitro de brotações

Observou-se um aumento linear no número e comprimento médio de raízes à medida em que se adotou maiores concentrações de ANA adicionadas ao meio de cultura (Figura 1).

$\mathrm{O}$ aspecto visual de uma plântula de gérbera em meio de cultura para indução de enraizamento e enraizada in vitro observa-se na Figura 2.

Pierik \& Sprenkels (1984), trabalhando com as cultivares Fleur e Florence, utilizando o meio MS suplementado com AIA nas concentrações variando de 3 a $10 \mathrm{mg} \mathrm{L}^{-1}$ e ANA a 1 ou $3 \mathrm{mg} \mathrm{L}^{-1}$, observaram que o ANA proporcionou $100 \%$ de enraizamento, com mais raízes por broto, para ambas as cultivares, em comparação com o efeito do AIA, e que altos porcentuais de brotos enraizados foram alcançados também com o emprego do
AIA, porém esse não apresentou diferença significativa no enraizamento, em comparação com o tratamento sem auxina.

\section{Aclimatização de Plântulas}

A cobertura das plantas com sacos plásticos durante o período de aclimatização foi eficiente, já que a absorção e a perda de água mostraram-se completamente reguladas, não sendo observado estado de murcha durante o período de aclimatização. O porcentual de sobrevivência foi de $100 \%$.

Santana (2003), relata que a manutenção da alta umidade relativa no microambiente durante a aclimatização de plântulas de Annona glabra L. resulta em um aumento no porcentual de sobrevivência das plântulas.

Aspectos gerais das plântulas de Gerbera jamesonii cv. Jaguar Cream, aos 14 dias após a aclimatização, podem ser visualizados na Figura 3.
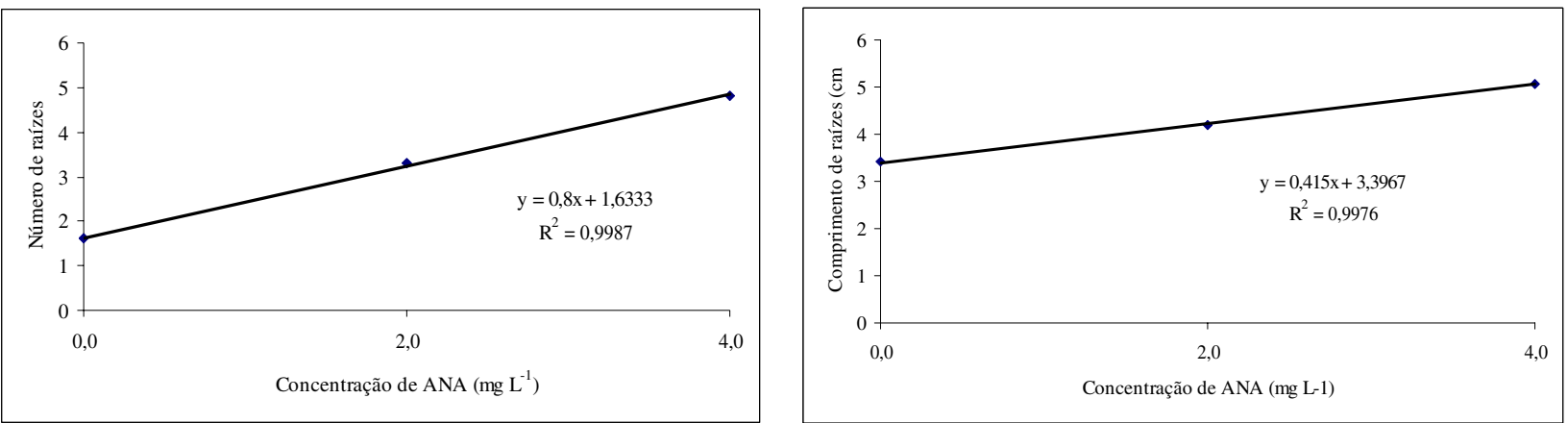

Figura 1 -Número de raízes/explante (A) e comprimento médio de raízes (cm) (B) em brotações de Gerbera jamesonii cv. Jaguar Cream, em função de diferentes concentrações de ANA.
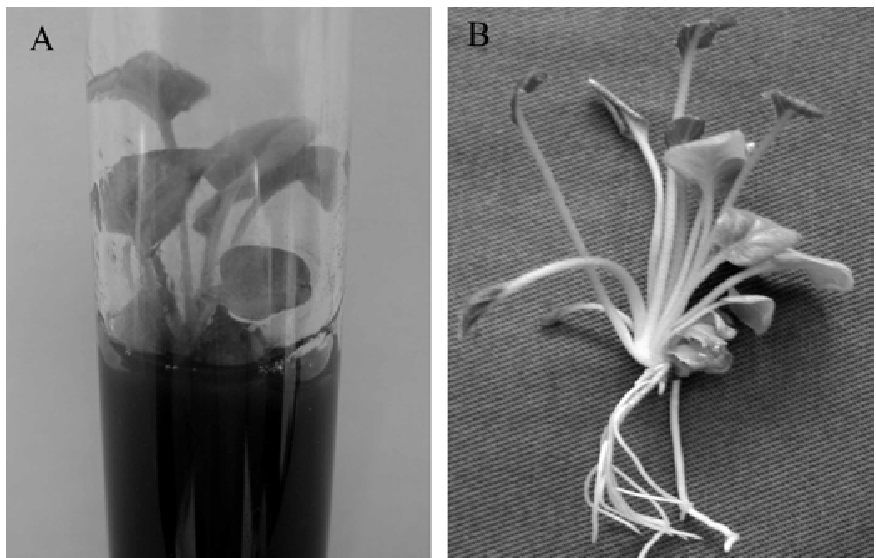

Figura 2 - (A) - Plântula de Gerbera jamesonii cv. Jaguar Cream em meio de cultura para enraizamento, suplementado com 4,0 mg L ${ }^{-1}$ de ANA. (B) - Plântula enraizada em condições in vitro. 


\section{Anatomia de folhas produzidas por cultivo in vivo e in vitro}

As folhas do cultivo in vitro apresentaram feixes vasculares do tipo colateral pouco diferenciados, ao contrário do cultivo in vivo, onde esses se apresentam em maior número e grau de diferenciação. $\mathrm{O}$ número de células do parênquima cortical é maior no cultivo in vivo que no in vitro. O colênquima está presente in vivo e ausente in vitro (Figura 4 A e C).

Santos (2001), observou que a nervura central de folhas de cafeeiro (Coffea arabica L. 'Rubi' e Coffea canephora Pierre ex Froehn 'Apoatã'), obtidas pelo cultivo in vitro apresentou células do xilema em menor número, tamanho e espessura que as células do xilema da nervura central de folhas cultivadas in vivo.

Quanto as seções transversais das lâminas foliares de gérbera, observou-se que, em ambos os cultivos (in vivo e in vitro), o mesofilo já se encontra diferenciado nos dois tipos de parênquima clorofiliano (parênquima paliçádico e parênquima esponjoso ou lacunoso). O mesofilo é dorsiventral, apresentando parênquima paliçádico na face superior da lâmina foliar (adaxial) e parênquima esponjoso na face inferior (abaxial) (Figura $4 \mathrm{~B}$ e D).

No cultivo in vivo, o parênquima paliçádico é constituído de uma a duas camadas de células compactas e alongadas e o parênquima esponjoso ou lacunoso constituído de sete à oito camadas de células. Já no cultivo in vitro o parênquima paliçádico apresenta-se também com uma ou duas camadas de células, mas em menor grau de diferenciação. O parênquima esponjoso é constituído de seis a sete camadas de células.

Todas as variáveis analisadas: epiderme adaxial, parênquima paliçádico, parênquima esponjoso e epiderme abaxial, apresentaram espessura significativamente menor para o cultivo in vitro em comparação ao cultivo in vivo (Tabela 2).

Em estudos anatômicos de murici-pequeno, Nogueira (2003) também encontrou espessuras significativamente menores de epiderme adaxial, parênquima paliçádico e epiderme abaxial para o cultivo in vitro, em relação ao cultivo in vivo.

Nota-se ainda que, em ambas as condições de cultivo, as epidermes abaxial e adaxial são compostas por apenas uma camada de células (epiderme uniestratificada), revestidas pela cutícula, sendo essa mais espessa nas folhas de plantas cultivadas in vivo.

A presença da cutícula no cultivo in vitro é fator importante na micropropagação, uma vez que evita a perda excessiva de água da planta para o ambiente e, conseqüentemente, favorece a sobrevivência das plântulas
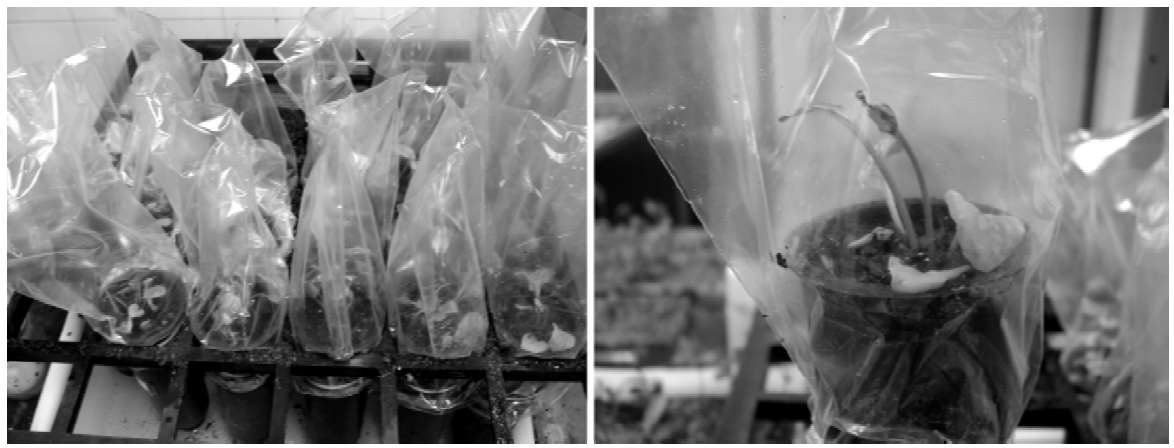

Figura 3 - Plântulas de Gerbera jamesonii cv. Jaguar Cream em aclimatização.

Tabela 2 - Efeito do tipo de cultivo (in vivo e in vitro) sobre a espessura da epiderme adaxial, do parênquima paliçádico, do parênquima esponjoso e epiderme abaxial de lâminas foliares de Gerbera jamesonii cv. Jaguar Cream.

\begin{tabular}{ccccc}
\hline \multirow{2}{*}{ Tipo de cultivo } & \multicolumn{4}{c}{ Espessuras médias observadas $(\mu \mathrm{m})$} \\
\cline { 2 - 5 } & Epiderme adaxial & Parênquima paliçádico & Parênquima esponjoso & Epiderme abaxial \\
\hline In vivo & $23,64 \mathrm{a}$ & $71,55 \mathrm{a}$ & $144,48 \mathrm{a}$ & $17,61 \mathrm{a}$ \\
In vitro & $19,02 \mathrm{~b}$ & $61,71 \mathrm{~b}$ & $126,00 \mathrm{~b}$ & $15,15 \mathrm{~b}$ \\
\hline
\end{tabular}

*Médias seguidas por letras distintas na coluna diferem entre si, a 1\% de probabilidade, pelo teste de F. 


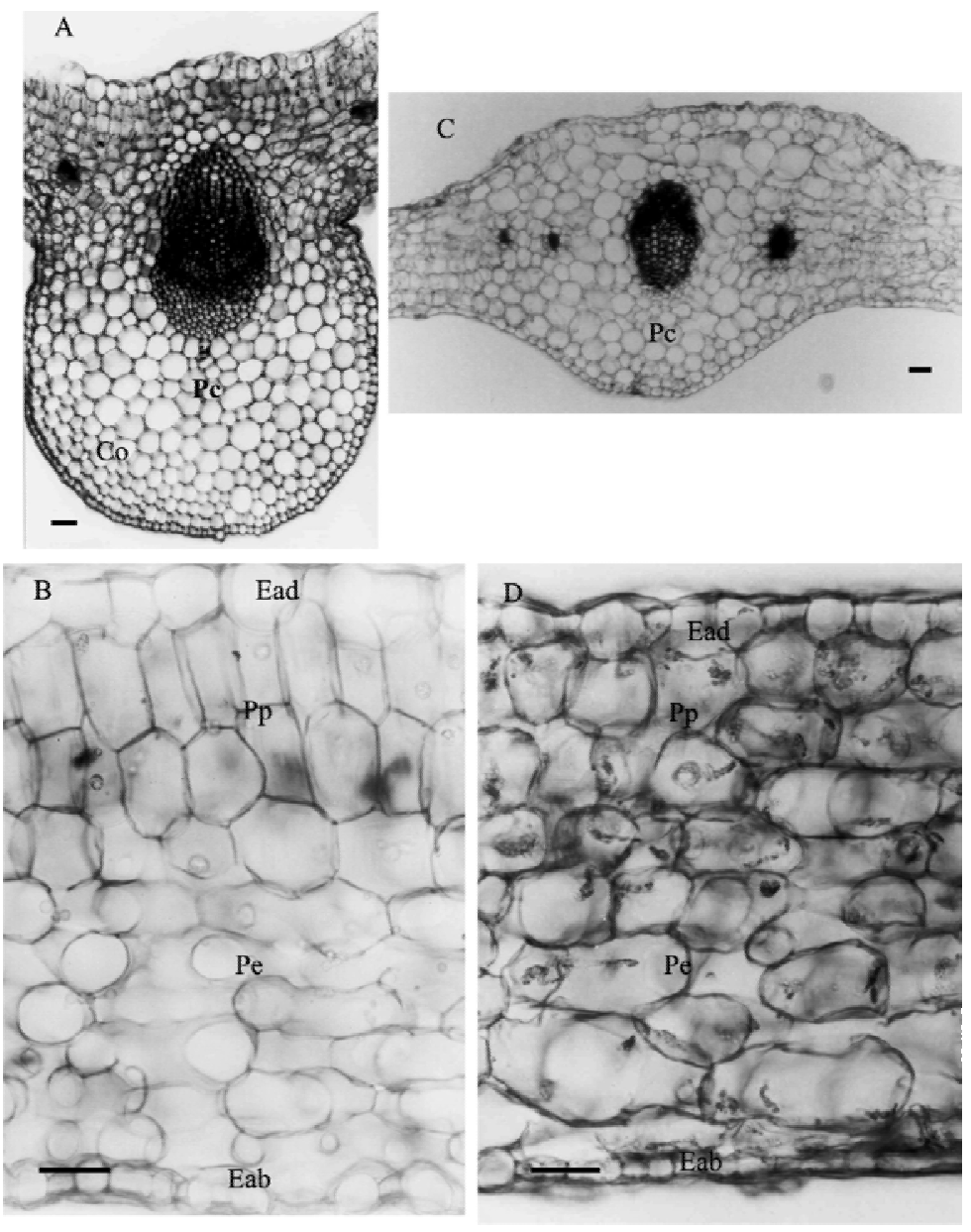

Figura 4 - Seções transversais da nervura central e lâminas foliares obtidas de folhas de gérbera cultivada in vivo (A e $\mathrm{B})$ e in vitro (C e D), evidenciando parênquima cortical $(\mathrm{Pc})$, colênquima (Co), epiderme adaxial (Ead), parênquima paliçádico $(\mathrm{Pp})$, parênquima esponjoso $(\mathrm{Pe})$ e epiderme abaxial (Eab). A barra na figura equivale a $50 \mu \mathrm{m}$.

micropropagadas durante o processo de aclimatização, na condição ex vitro.

As diferentes condições ambientais in vitro e in vivo podem ter contribuído para justificar as diferenças observadas na estrutura foliar.

\section{CONCLUSÕES}

Obteve-se um protocolo eficiente de micropropagação por organogênese indireta em capítulos florais de Gerbera jamesonii cv. Jaguar Cream, bem como sucesso na aclimatização de plântulas.

Em gérbera, o sistema vascular em folhas produzidas in vivo é mais desenvolvido que in vitro.

As estruturas foliares de gérberas desenvolvidas in vivo apresentam cutícula, epiderme adaxial, parênquima paliçádico, parênquima esponjoso e epiderme abaxial mais espessos que no cultivo in vitro.

\section{REFERÊNCIAS BIBLIOGRÁFICAS}

ARELLO, E. F. Gérbera (Gerbera jamesonii Bolus ex Hook). In: TOMBOLATO, A. F. C.; COSTA, A. M. M. Micropropagação de plantas ornamentais. Campinas: Instituto Agronômico, 1998. p. 29-31. (Boletim técnico, 174).

BUKATSH, F. Benerkemgem zeir doppelfarbeing astrablausafranina. Mikrokosmos, Stuttgart, v. 61, p. 255, 1972.

DEBERGH, P. C.; MAENE, L. J. A scheme for the commercial propagation of ornamental plants by tissue culture. Scientia Horticulturae, Amsterdam, v. 14, n. 4, p. 335-345, 1981. 
DEBERGH, P. C.; MAENE, L. J. Pathological and physiological problems related to in vivo culture of plant. Parasitica, Gembloux, v. 40, n. 1, p. 69-75, 1984.

GEORGE, E. F.; SHERRINGTON, P. D. Plant propagation by tissue culture : handbook and diretory of commercial laboratories. Eversley: Exegtics, 1984.

GRATTAPAGLIA, D.; MACHADO, M. A. Micropropagação. In: TORRES, A. C.; CALDAS, L. S.; BUSO, J. A. (Eds.). Cultura de tecidos e transformação genética de plantas. Brasília, DF: Embrapa-SPI/EmbrapaCNPH, 1998. v. 1, p. 183-260.

HICKS, G. S. Patterns of organ developmental in plant tissue cultureand the problem of organ determination. The Botanical Review, New York, v. 46, n. 1, p. 1-23, Mar. 1980.

JOHANSEN, B. A. Plant microtechnique. New York: McGrawn-Hill, 1940. 433 p.

MURASHIGE, T.; SKOOG, F. A revised medium for rapid growth and bioassays with tobacco tissue cultures. Physiologia Plantarum, Copenhagen, v. 15, n. 3, p. 473497, Mar. 1962.

NOGUEIRA, R. C. Propagação in vitro, análises anatômicas e biquímicas de murici-pequeno (Byrsonima intermedia A. Juss.). 2003. 88 p. Dissertação (Mestrado em Fisiologia Vegetal) - Universidade Federal de Lavras, Lavras, 2003.

PASQUAL, M.; HOFFMANN, A.; RAMOS, J. D. Cultura de tecidos vegetais: tecnologia e aplicações: introdução: fundamentos básicos. Lavras: UFLA/FAEPE, 1997. $159 \mathrm{p}$.

PIERIK, R. L. M.; JANSEN, J. L. M.; MAASDAM, A.; BINNENDIJK, C. M. Optimalization of gerbera plantlet production from excised capitulum explants. Scientia Horticulturae, Wageningen, v. 3, n. 4, p. 351-357, 1975.

PIERIK, R. L. M.; SPRENKELS, P. A. Improvement of the rooting of gerbera in vitro by NAA. Vakblad voor de Bloemisterij, Wageningen, v. 39, n. 21, p. 45, 1984.
REZENDE, R. K. S. Aspectos do cultivo in vitro e divergência genética em gérbera (Gerbera jamesonii). 2005. 91 p. Dissertação (Mestrado em Fisiologia Vegetal) Universidade Federal de Lavras, Lavras, 2005.

ROHR, R.; HANUS, D. Vegetative propagation of wavy grain sycamore maple. Canadian Journal of Forestry Research, Ottawa, v. 17, n. 5, p. 418-420, May 1987.

SANTANA, J. R. F. Controle da morfogênese in vitro em algumas espécies de annonaceae. 2003. 237 p. Tese (Doutorado em Fisiologia Vegetal) - Universidade Federal de Lavras, Lavras, 2003.

SANTOS, C. G. Micropropagação e caracterização bioquímico-anatômica em Coffea arabica e Coffea canephora. 2001. 110 p. Dissertação (Mestrado em Fisiologia Vegetal) - Universidade Federal de Lavras, Lavras, 2001.

SASS, J. Botanical microtechnique. Iowa: Iowa College, 1951. $228 \mathrm{p}$.

SOARES, G. de A. Aspectos do cultivo in vitro do ingazeiro [Inga vera Willd. subsp. affinis (DC) T. D. Penn.]. 2003. 90 p. Dissertação (Mestrado em Fisiologia Vegetal) Universidade Federal de Lavras, Lavras, 2003.

STIRMART, D. P. Commercial micropropagation of florist flower crops. In: ZIMMERMAN, R. H. et al. (Eds.). Tissue culture as a plant production systems for horticultural crops. Dordrecht: M. Nijhoff, 1986. p. 301-315.

TORRES, A. C.; CALDAS, L. S.; FERREIRA, A. T. Retrospectiva da cultura de tecidos de plantas. In: TORRES, A. C.; CALDAS, L. S.; BUSO, J. A. (Eds.). Cultura de tecidos e transformação genética de plantas. Brasília, DF: EmbrapaSPI/Embrapa-CNPH, 1998. v. 1, p. 11-20.

ZIMMERMAN, R. H. Micropropagation of fruit plants. Acta Horticulturae, Wageningen, n. 120, p. 217-222, 1981.

ZIV, M. In vivo hardening and acclimatization of tissue plants. In: WITHERS, L. A.; ALDERSON, P. G. (Eds.). Plant tissue culture and its agricultural applications. London: Butterworths, 1987. p. 187-196. 